\title{
Lightness Compression and Hue Changes
}

\author{
Julio Lillo and Humberto Moreira \\ Universidad Complutense de Madrid
}

Two experiments were performed to relate the Bezold-Brücke (B-B) and lightness compression effects. The first used a calibrated screen to present an achromatic luminance staircase. In addition, it reproduced, the methodology and the essential aspects the lightness compression effect discovered by Cataliotti and Gilchrist (1995). That is, observers perceived a truncated grey scale (from white to medium grey) when the staircase was the only stimulation in the near background (Gelb condition), but not when presented on a Mondrian background, because of the high articulation level provided by this background. Experiment 1 design also included two other backgrounds that produced a partial compression effect. In Experiment 2, two chromatic staircases were used. Employing a naming task, changes in hue perception were only observed for the susceptible staircase. The observed changes were of two types. First, for the full staircase presentations, a Gelb background produced maximum lightness compression (more similarity in the lightness of the staircase stimuli) and, also, a minimum B-B effect (fewer differences in hue). Second, only for the Gelb condition, there were changes in the hue of the lowest luminance staircase stimuli depending on the staircase extension. Results are discussed in the framework of the anchoring theory of lightness perception.

Keywords: color, articulation, Bezold-Brücke, lightness

Se realizaron dos experimentos para relacionar el efecto Bezold-Brücke y el de compresión de la claridad. En el primero se utilizó un monitor calibrado para presentar una escalera acromática de luminancias. Aparte de ello, el experimento reprodujo la metodología y los aspectos esenciales del efecto de compresión de la claridad descubierto por Cataliotti y Gilchrist (1995). Esto es, los observadores percibieron una escala de grises truncada (del blanco al gris medio) cuando la escalera fue la única estimulación presentada en el entorno próximo (condición Gelb), pero no cuando se presentó sobre un Mondrian, debido al alto nivel de articulación proporcionado por este fondo. El diseño del primer experimento también incluyó otros dos fondos que produjeron un efecto de compresión parcial. En el segundo experimento se utilizaron dos escaleras cromáticas. Una tarea de denominación permitió apreciar cambios en la percepción del matiz sólo en la escalera susceptible. Los efectos observados fueron de dos tipos. Primero, cuando se presentó la escalera completa, se observó que el fondo Gelb produjo una máxima compresión de la claridad (máxima similitud entre los estímulos de la escalera) y, también, un grado mínimo de efectos B-B (menos diferencias en matiz). Segundo, sólo para la condición Gelb hubo cambios en el matiz del estímulo de menor luminancia de la escalera, dependiendo de la extensión de la escalera. Los resultados se comentan en el marco de referencia proporcionado por la teoría del anclaje de la percepción de la claridad.

Palabras clave: color, articulación, Bezold-Brücke, claridad

Correspondence should be addressed to Dr. Julio Lillo Jover. Departamento de Psicología Diferencial y del Trabajo. Facultad de Psicología. Universidad Complutense de Madrid. Campus de Somosaguas. 28223. Madrid (Spain). Tel: + 3491943198. Faculty: + 34 913942830. E-mail: julillo@psi.ucm.es 
The scientific community considers hue, lightness, and chroma as the three necessary and sufficient dimensions for a full description of surface colors (Kayser \& Boynton, 1996, Wyszecki \& Stiles, 1982). Hue is concerned with the more qualitative aspects of chromatic experience. In the framework of the CIE parameters (Hunt, 1991, chap. 3), it is usually assumed that hue can be specified by $\mathrm{H}^{*}(\mathrm{H}$ is the first letter of "hue") but, as shown elsewhere (Lillo, Aguado, Moreira, \& Davies, 2004), there is only a partial correspondence between $\mathrm{H}^{*}$ and hue, and it can be concluded that $\mathrm{H}^{*}$ is only an alternative way of naming the chromatic angle of a stimulus. This latter variable, although related to hue, is not equivalent to it. More specifically, although it is true that $\mathrm{H}^{*}$ variations produce hue changes (i.e., changing from $\mathrm{H}^{*}=155^{\circ}$ to $\mathrm{H}^{*}=255^{\circ}$ changes the hue from green to blue), it is also true than hue variations can be generated by changing lightness, even when $\mathrm{H}^{*}$ remains constant (i.e., for stimuli with $\mathrm{H}^{*}=70^{\circ}$, a change from light to dark transforms hue perception from yellow to green-brown; Lillo et al., Tables 1 and 2). Change in hue derived from luminance variations (and, consequently, lightness variations) is usually called the "Bezold-Brücke" effect (hereafter the B-B effect).

Lightness is concerned with the more quantitative aspects of chromatic experience. In the framework of the CIE parameters, it is specified by $\mathrm{L}^{*}$, a parameter related to standard luminance (1) as indicated by Equation 1:

$$
\mathrm{L}^{*}=\left(\frac{l}{l_{n}}\right)^{1 / 3}-116
$$

According to Equation 1, lightness ( $\mathrm{L}^{*}$ ) only depends on comparing $\left(l / l_{\mathrm{n}}\right)$, the luminance (1) of a surface with the luminance corresponding to the reference white $(\mathrm{ln})$. This equation simplifies excessively what the visual system does to compute lightness, because it does not take into account the influence of local factors, nor factors related to the visual space segmentation (there is no theoretical orientation to know which stimulus is the reference white). This latter aspect is the core of the anchoring theory of lightness perception (Gilchrist et al., 1999).

According to the anchoring theory, the explanation of lightness perception requires responding to anchoring and scaling problems. Anchoring is concerned with the localization of luminance values in relation to the grey scale (Which luminance is perceived as white?). The scaling problem is concerned with the way luminance values are distributed on the grey scale (How much luminance variation is required to produce a specific change in the grey scale?). To answer these two problems, the anchoring theory uses the concepts of "framework," "belongingness," and "articulation." More specifically, it postulates that: (a) The lightness of a surface results from comparing its luminance with the one that becomes the reference (the anchor, "the luminance value that appears white", op. cit., p. 804) for the frameworks to which it "belongs"; (b) correspondence between the different grey experiences (from white to black) and the different luminance levels depends on all the frameworks to which a specific surface belongs (belongingness is a hierarchical concept). Consequently, the various luminance levels (from maximum to minimum) in the related frameworks will cover the full gamut of grey levels (from white to black); (c) the more articulated a framework is, the more it is perceptually segregated from the rest of the scene and the more independently are its luminances used to resolve the anchoring and the scaling problems.

The anchoring theory can explain the lightness compression effect found by Cataliotti and Gilchrist (1995; see also Gilchrist \& Cataliotti, 1994) when presenting a luminance staircase in the context of experimental settings similar to the ones used in the famous Gelb demonstration (Gelb, 1929/1938; hereafter the "Gelb effect"). Even more, this theory is also able to explain why the lightness compression effect does not appear when the luminance staircase is presented on a Mondrian pattern. More specifically, the theory predicts that, because of its high articulation, the Mondrian background generates a vigorous local framework that segregates the plane containing the luminance staircase from the rest of the scene and, consequently, allows the full grey scale (from white to black) to be experienced in response to the staircase luminances.

Our main research goal was to establish a bridge between the B-B effect and Cataliotti and Gilchrist's (1995) lightness compression effect. We were also interested in evaluating whether, as predicted by the anchoring theory, local mechanisms (as lateral inhibition) are irrelevant to explain Cataliotti and Gilchrist's lightness compression effect. To achieve these goals, two experiments were performed. The first one was essentially a replication of Gilchrist and Cataliotti's (1994) experimental procedure, using only achromatic stimuli. Its main novelty was the use of a calibrated screen monitor to present the target stimuli. The second experiment used chromatic stimuli because we were interested in knowing whether articulation influences not only lightness but also hue perception.

\section{Experiment 1. Articulation, Local Factors and Lightness Perception}

As previously indicated, we emulated the experimental arrangements of Gilchrist and Cataliotti in their essential aspects. It is now time to make them explicit.

The luminance staircase they used was formed by five achromatic stimuli. There was a 30:1 ratio between the reflectances of the lighter and the darker stimuli. Because the staircase was uniformly illuminated, this ratio also appeared in its luminance range. 
In the Gelb condition, Gilchrist and Cataliotti's (1994) experimental setting mimicked most of the spatial arrangements used by Gelb (1929/1938). They can be specified as follows: (a) No other stimuli were presented in the spatial plane (hereafter the near framework) where the luminance staircase appeared; (b) although this plane was highly illuminated, it had a low apparent illumination; (c) similar to the one used in their proximities (hereafter the intermediate framework).

Gilchrist and Cataliotti (1994) used an asymmetric lightness matching procedure to measure the lightness of every square included in the luminance staircase. This procedure required observers to select from a reference set the stimulus that was most similar in lightness to the target. The reference set was located on a plane, highly illuminated, near the observer but far from the luminance staircase.

The number of stimuli included in the reflectanceluminance staircase changed between trials. In an extreme condition, only one stimulus (the one with the lowest reflectance) was presented and, consequently, the experimental settings were identical to Gelb's most wellknown setting. In this condition, as expected and concordantly with Gelb's results, this stimulus was perceived as white. As also expected, the increase in the number of stimuli included in the staircase made it appear darker but, it must be emphasized, not as dark as would be expected from the range of luminances-reflectances used. More specifically, for the five-stimulus condition, there was a 30:1 reflectance-luminance variation between the lighter and the darker stimuli. This variation, as known by any Munsell Atlas user, usually produces the perception of a full grey scale (extended from white to black) in conventional observation conditions. In contrast, the Gelb condition produced a lightness compression effect because only a truncated grey scale (from white to medium grey) was perceived.

From the anchoring theory (Gilchrist et al., 1999), the lightness compression produced by the Gelb background is explained considering that: (a) Because of the apparent illumination, the luminance staircase was perceived as belonging to two frameworks: the near one and the intermediate one; (b) because the intermediate framework reduced illumination level, the near framework always provided the maximum luminance. Such luminance was perceived as white and became the lightness anchor; (c) the full range of greys was experienced in response to the

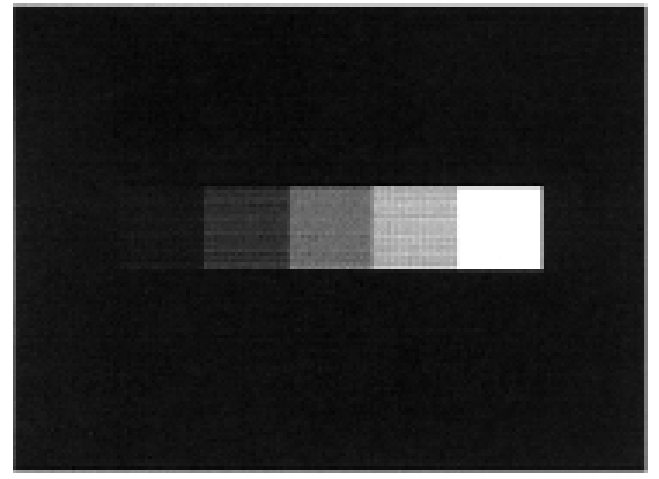

A. Gelb

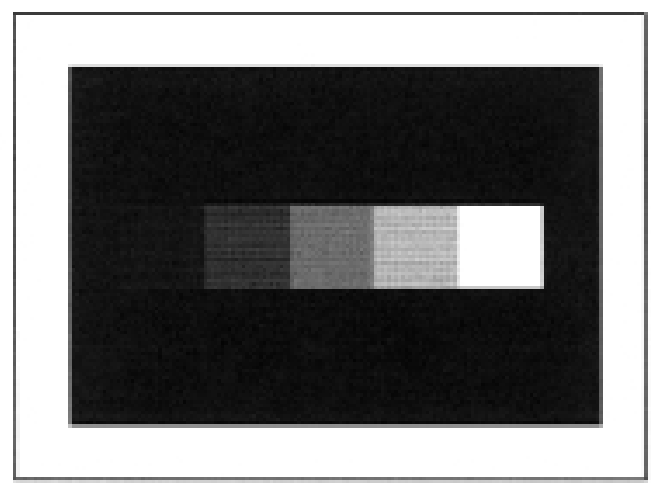

C. White insulation

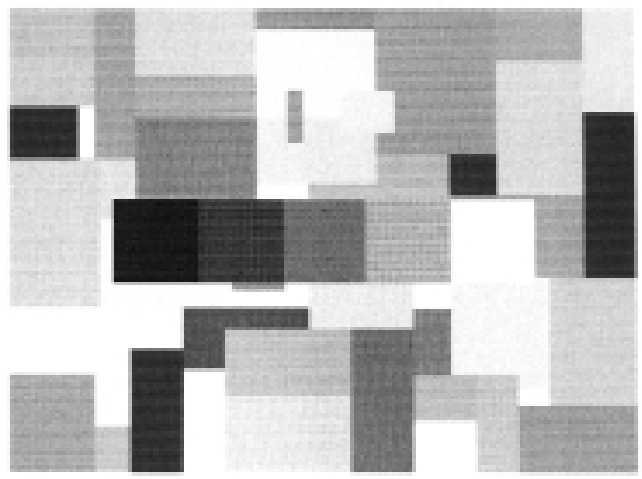

B. Mondrian

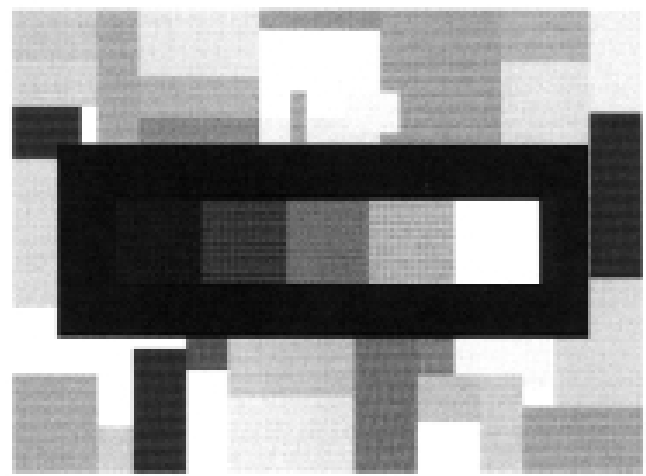

D. Nonadjacent Mondrian

Figure 1. Backgrounds and luminance staircases. Experiment 1 presented the staircase on four different backgrounds: $\mathrm{A}=\mathrm{Gelb}, \mathrm{B}=$ Mondrian, $\mathrm{C}=$ White insulation, and $\mathrm{D}=$ Nonadjacent Mondrian. The last background was not used in Experiment 2, where the number of squares was reduced to three (the two extreme ones were not used). 
luminance variations provided by the near and the intermediate frameworks. Because of this, the luminance staircase (presented in the near framework) did not produce the perception of black or of dark greys (supposedly, they were perceived in response to the luminances provided by the intermediate framework.

Gilchrist and Cataliotti (1994) also used an experimental condition where the luminance staircase was presented on a Mondrian pattern. This condition provided results fully consistent with the anchoring theory explanation of the lightness compression effect. According to this, the articulation provided by the Mondrian background produced perceptual segregation of the intermediate and the near frameworks and, consequently, only the luminance values contained in the near framework were relevant to solve the anchoring and the scaling problems related to the luminance staircase perception.

Our first experiment used four near backgrounds (see Figure 1). Two backgrounds (Gelb and Mondrian) were similar to their equivalents in Gilchrist and Cataliotti's (1994) experiments. The other two backgrounds were introduced to evaluate the possible influence of local factors (nonadjacent Mondrian) and to study a possible alternative way of segregating the near and the intermediate background (white insulation).

The white insulation background (see Figure 1.C) was similar to the Gelb one (see Figure 1.A), except that we used a white frame around the background perimeter. We decided to use this because Uchikawa, Uchikawa, and Boynton (1989) observed the efficacy of a similar manipulation for changing lightness and hue (i.e., some stimuli changed from orange to brown). We expected the presence of the white frame to promote the perceptual segregation between near and intermediate frameworks.

The last background (see Figure 1.D) was called nonadjacent Mondrian because it included a minimum luminance ring to eliminate the visual contact between the staircase and the Mondrian background. If local factors (such as those related to lateral inhibition) are irrelevant to explain the capacity of the Mondrian pattern to prevent the lightness compression effect, then the presence or absence of the black ring must also be irrelevant.

\section{Method}

\section{Participants}

Ten participants (seven females and three males) took part in the experiment. They were between 24 and 48 years of age $(M=27.22, S D=5.95)$. All were screened for normal color vision by means of the Ishihara Pseudo-Isochromatic color plates and the City University Color Vision Test (CUCVT; Fletcher, 1980). None of the participants was color blind. All the participants had normal, or corrected to normal, acuity vision.

\section{Stimuli and Apparatuses}

Figure 2 shows the experimental room arrangement seen from the top. The calibrated screen used to present the luminance staircase was located in front of the participant at a distance of $2 \mathrm{~m}$. It was placed inside a cubic box $(56.5$ $\times 51 \mathrm{~cm})$ painted medium grey $\left(\mathrm{L}^{*}=50\right)$. This box had an aperture $(32.5 \times 24 \mathrm{~cm})$ to allow only the visibility of the screen. Near the participant, there was a table with the achromatic reference set.

We used a calibrated screen (Sony Trinitron Multiscan 17 SEII) to present the luminance staircase. The screen calibration and all the photo-colorimetric measurements were performed using a Photoresearch PR-650 spectraradiometer and a Minolta CS-100 colorimeter. The luminance staircase was formed by five achromatic squares ( $\mathrm{u}^{\prime}=0.21, \mathrm{v}=0.47$ ). Their luminances were: $2.19,8.71,21.78,45.57$, and 63.35 $\mathrm{cd} / \mathrm{m}^{2}$.

This range provided a ratio of, approximately, 30:1 $(63.35 / 2.19=29.84)$. This variation was equivalent to the one provided by a set of achromatic surface colors with reflectances equal to: $3 \%, 12 \%, 30 \%, 60 \%$, and $90 \%$ illuminated with, approximately, 220 lx. Each square side measured $5.5 \mathrm{~cm}$ and projected a visual angle of $1.6^{\circ}$. Every luminance level was always presented in the same position, the one indicated in Figure 1 (lowest luminance at the right, highest at the left). The white frame (see Figure 1.C) measured $32.5 \times 24 \mathrm{~cm}\left(9.23 \times 6.84^{\circ}\right)$ on the outer perimeter and $29.5 \times 16 \mathrm{~cm}\left(8.39 \times 4.57^{\circ}\right)$ on the inner one. The minimum luminance ring (see Figure 1.D) measured $32 \times$ $10 \mathrm{~cm}\left(9.09 \times 2.86^{\circ}\right)$ on the outer perimeter and $28 \times 6 \mathrm{~cm}$ $\left(7.97 \times 1.72^{\circ}\right)$ on the inner one.

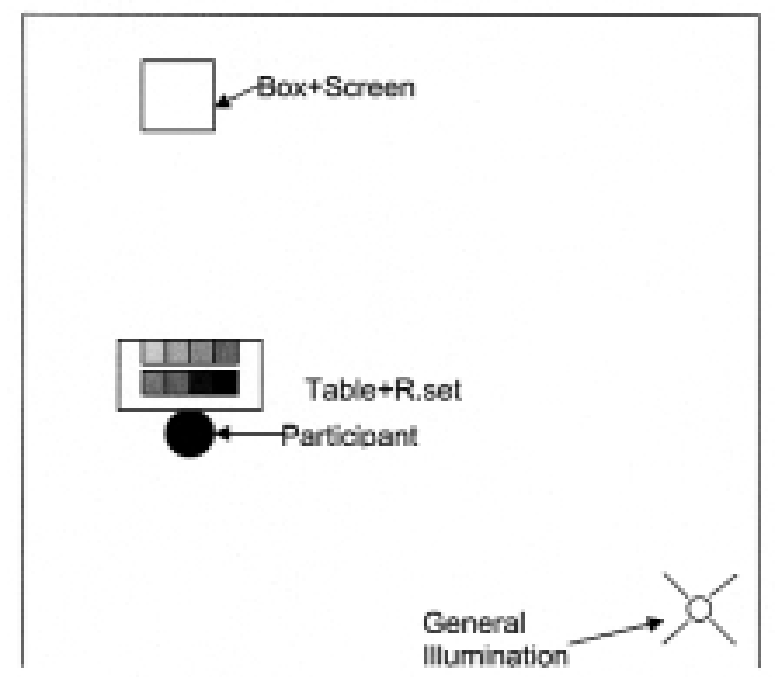

Figure 2. Experimental room spatial arrangement (seen from the top). A screen, used to present the luminance staircase, was located in front of the participant. Near the participant, there was a table with the reference set. General room illumination was provided by an incandescent lamp located behind the participant. 
The reference set was presented on a grey surface $\left(\mathrm{L}^{*}\right.$ $=50$ ) located on a table near the participant. A halogen lamp equipped with color temperature correction filters provided a $5500 \mathrm{~K}$ correlated color temperature and an illuminance approximately equal to $4000 \mathrm{~lx}$. The reference set was formed by the 18 achromatic ("N") tiles provided by the NCS (from S 9000-N to S-0500-N) presented on a $42 \times 30$ $\mathrm{cm}$ white surface.

General room illumination was provided by an OsramHalolux 150V incandescent lamp located near the ceiling. It supplied an illuminance of $2.5 \mathrm{~lx}$ in the screen plane. Color correction filters allowed us to equate color temperature to the reference set illumination $(5500 \mathrm{~K})$. The screen plane had a $4.51 \mathrm{x}$ illumination because of the sum of the general room illumination and the light provided by the indirect halogen lamp used to illuminate the reference set.

\section{Design and Procedure}

A $5 \times 4$ (Number of Staircase Squares $\times$ Number of Backgrounds) intragroup design was used. The number of squares in the staircase changed between trials from 1 (only the dark stimulus) to 5 (the full staircase). For partial staircases (less than 5 squares), only the lowest luminances were used (i.e., in the 3-staircase condition, only 2.19, 8.71 , and $21.78 \mathrm{~cd} / \mathrm{m}^{2}$ ). The staircases (full or partial) were presented on the four backgrounds reproduced in Figure 1.

Ten random orders (one for every participant) were created. Each order included the 20 experimental conditions resulting from combining the 5 possible staircases (1 to 5 squares) with the 4 backgrounds. An asymmetric lightness matching procedure was used. Participants were requested to indicate, from the stimuli contained in the reference set, the one most similar to each staircase's square.

\section{Results}

Figures 3 and 4 display the most important results provided by Experiment 1 . Figure 3 corresponds to the trials where the full staircase was presented.

The abscissa in Figure 3 indicates the logarithm of the ratio between the luminance of a square $(\mathrm{Y})$ and the maximum value in the full staircase (Yn). The ordinate of Figure 3 corresponds to the mean of the matching. The continuous line has a slope equal to $1(b=1)$ and indicates a perfect (hypothetical) correspondence between the staircase luminance variation and the reflectance of the selected surfaces (perfect constancy). Discontinuous lines correspond to the empirical results (means) for the four backgrounds. Regarding the black triangle line, it can be observed that the Mondrian condition produced a very similar performance
( $b=.88, r^{2}=.96$ ) to the one indicated by the perfect constancy line. Consequently, this background produced the experience of a full grey scale (from white to black). On the other hand, for the Gelb background (black circles), the slope of the convergence line was much reduced $(b=$ $.454, r^{2}=.867$ ) indicating the presence of a strong lightness compression effect. That is, participants only experienced a truncated grey scale where black and darks grays did not appear.

The discontinuous lines corresponding to the white insulation $\left(b=.578, r^{2}=.876\right)$ and the nonadjacent Mondrian $\left(b=.624, r^{2}=.925\right)$ backgrounds were approximately halfway between the Gelb and Mondrian backgrounds. Thus, a partial lightness compression was observed for these two intermediate conditions.

A repeated measures ANOVA was performed to compare the selections obtained in the four backgrounds in response to the lowest luminance stimulus of the full staircase (their means are the leftmost points of the four discontinuous lines from Figure 3 ). We observed that the background type produced significant differences, $F(1,31)$ $=51.48, p<.05$. All the possible comparisons of pairs were significant $(p<.05)$, except for the comparison of the white insulation and the nonadjacent Mondrian backgrounds. Consequently, the stimulus reflectances selected in response to the Mondrian pattern were significantly inferior to the other three conditions, and the

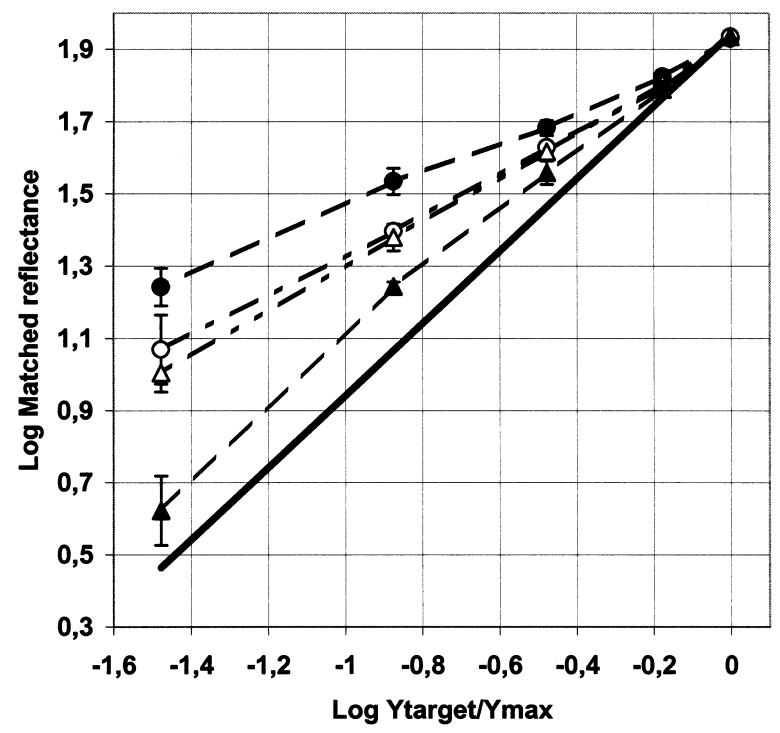

Figure 3. Asymmetric lightness matching for the full staircase presentation in Experiment 1. The abscissa corresponds to the logarithm of the ratio between the square luminance $(\mathrm{Y})$ and the staircase maximum luminance (Yn). The ordinate indicates matched luminances. Continuous lines correspond to a perfect correspondence between presented luminances and matched reflectances. Gelb $=$ black circles, Mondrian = black triangles, Nonadjacent Mondrian $=$ white triangles, and White insulation $=$ white circles. 
opposite can be said for the Gelb condition. (The white insulation and the nonadjacent Mondrian reflectance selections were significantly lower than the Gelb and significantly higher than the Mondrian).

Figure 4 indicates the changes in the appearance of the lowest luminance stimulus as the number of the stimuli in the staircase increased. For every line, the most leftward point corresponds to its sole presentation and the most rightward to when it was presented in the full staircase. It can be observed that the slopes for the Mondrian $(b=-.038$, $\left.r^{2}=.005\right)$, the nonadjacent Mondrian $\left(b=-.063, r^{2}=.049\right)$, and the white insulation $\left(b=-.034, r^{2}=.009\right)$ backgrounds are near to zero and, consequently, indicate that the appearance of the stimulus did not change appreciably with the increase in the number of staircase squares. On the other hand, the Gelb condition $\left(b=-.307, r^{2}=.597\right)$ provided a slope showing that the lowest luminance stimulus became darker as the staircase extension increased.

A repeated measures parametric ANOVA was performed for every background type. They indicated that the reflectances selected in response to the lowest luminance stimulus did not change significantly $(p>.05)$ as the staircase grew larger on the Mondrian and white insulation backgrounds. On the other hand, the reflectances changed for the Gelb, $F(4)=45.97, p<.05$, and the nonadjacent Mondrian backgrounds, $F(4)=3.82$, $p<.05$. In the case of the Gelb background, a multiple

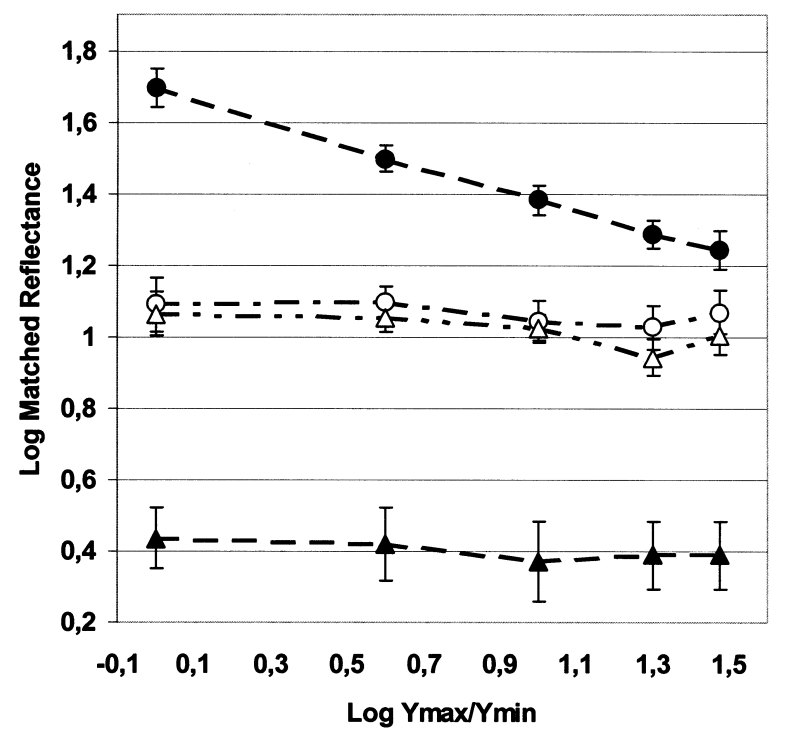

Figure 4. Changes in the appearance of the lower luminance stimulus in Experiment 1. The abscissa indicates the logarithm of the ratio between the target luminance (Ymin) and the staircase maximum luminance (Ymax). The ordinate indicates matched reflectances. For every line, the most leftward point corresponds to the sole presentation of the lowest luminance stimulus. The most rightward point corresponds to its presentation in the full staircase. comparison analysis revealed that, in general, all the comparisons of pairs showed that significantly higher reflectances were selected as the number of stimuli of the staircase decreased $(p<.05)$. The only exception to this general pattern was the presence nonsignificant differences between, on the one hand, the full staircase condition and, on the other hand, the 3- and 4-step staircases. Concerning the nonadjacent Mondrian background, the only significant difference found was related to the comparison between the 1-step and the 4step staircases (log matched reflectance $=1.06$ and 0.94 , respectively).

\section{Discussion}

As predicted from the anchoring theory, in the Gelb condition, the 1-square staircase condition produced the selection of high-reflectance stimuli in the asymmetric matching task. The selections moved to darker stimuli as the number of squares increased (see Figure 4). This change was expected because the staircase provided all the luminance variations in the near framework and the anchor for the near and the intermediate frameworks.

Differences in the grey scale amplitude for Gelb and Mondrian backgrounds (see Figure 3) were also consistent with the anchoring theory, and with the notion that articulation (high for Mondrian, low for Gelb) determines the level of perceptual segregation between the near and the intermediate backgrounds and, inversely, susceptibility to the lightness compression effect.

The nonadjacent Mondrian and the white insulation conditions produced results partially concordant with the anchoring theory predictions. These conditions sometimes acted like the Mondrian and other times like the Gelb. As in the Mondrian condition, the appearance of the lowest luminance stimulus did not become darker with the increase in staircase extension (see Figure 4), with the sole exception of 1 step versus 4 steps for the nonadjacent Mondrian. On the other hand, when the full staircase was presented (see Figure 3), there was a clear lightness expansion effect, and a truncated grey scale was perceived. We have no a clear explanation for this discrepancy between both types of result.

Our results provide new evidence about the relevance of the near background spatial structure to explain lightness perception. It should be not forgotten that there were no changes in the staircase luminances but, because of the background and the number of staircase stimuli used (in the Gelb condition), important changes in lightness appeared. These changes lead us to conclude the usefulness of the experimental arrangement employed in Experiment 1 to achieve, in Experiment 2, our main research goal: to relate the B-B and the lightness compression effects. 
Experiment 2. Lightness Compression, Dominant Wavelength, and Hue Perception

A previous work (Lillo, Moreira, \& Gomez, 2002), showed an almost perfect correspondence between what the NCS color system calls "hue" and chromatic angle. Another study (Lillo et al., 2004), using the full stimuli set provided by an NCS atlas (SCI, 1997), detected B-B effects for an important number of NCS hue denominations. Very frequently, stimuli that were similar in chromatic angle but different in lightness were named with different hue terms.

Results provided by the two aforementioned works allowed us to design two chromatic staircases with only three luminance levels. The staircases included stimuli belonging, respectively, to the "Y" and "B" NCS-hues. We selected these two because the former $\left(\mathrm{Y}, \mathrm{H}^{*}=226^{\circ}\right.$, associated dominant wavelength $575 \mathrm{~nm}$ ) produces the B$B$ effect when changing stimulus luminance whereas the latter $\left(\mathrm{B}, \mathrm{H}^{*}=577^{\circ}\right.$, associated dominant wavelength 485 $\mathrm{nm}$ ) does not. To avoid ceiling effects in the asymmetric matching task, we decided that the staircase should be formed by stimuli with intermediate levels in luminance and chroma $\left(\mathrm{C}^{*}\right)$.

Because of the similarity in the results provided by the nonadjacent Mondrian and the white insulation backgrounds (see Figures 3 and 4), we decided to use only three backgrounds in Experiment 2. We expected them to generate three different lightness contraction effect levels in the two chromatic staircases: maximum (Gelb), intermediate (white insulation), and minimum (Mondrian). Conversely, B-B effects were expected only for Staircase Y because our previous work (Lillo et al., 2004) detected changes in naming terms when changing lightness only for this NCS-hue.

In order to measure lightness and hue perception, participants performed two different tasks. As in Experiment 1 , they had to select from a reference set the color most similar to each stimulus contained in the staircase (asymmetric matching task). Additionally, they also performed a huenaming task, in which the staircase stimuli must be described using one or two categories (i.e., "yellow-green").

\section{Method}

\section{Participants}

Ten participants (seven females and three males) took part in the experiment. They were between 23 and 48 years of age $(M=27.2, S D=2.5)$. They were screened for normal color vision by means of the Ishihara Pseudo-Isochromatic color plates and the City University Color Vision Test (CUCVT; Fletcher, 1980). No participants were color blind. All participants had normal, or corrected to normal, acuity vision.

\section{Stimuli and Apparatuses}

Except where explicitly indicated, all the experimental arrangements were identical to those described in Experiment 1.

Two chromatic staircases were used. They were presented using the calibrated screen, but their stimuli were identical, in photo colorimetric terms, to some surface stimuli contained in an NCS atlas (SIS, 1996). The first staircase (Y) was made up of stimuli similar, in luminance relative values and chromatic coordinates, to the following NCS samples (in parenthesis, the measured luminance and CIE u'v' chromatic coordinates): S $2030 \mathrm{Y}\left(Y=34.6\right.$, $u^{\prime}=.227$, $\left.v^{\prime}=.518\right) ; \mathrm{S} 3030 \mathrm{Y}\left(Y=26.4, u^{\prime}=.229, v^{\prime}=.520\right) ; \mathrm{S} 4030$ $\mathrm{Y}\left(Y=18.4, u^{\prime}=.232, v^{\prime}=.520\right)$. The second staircase $(\mathrm{B})$ was made up of stimuli similar to: $\mathrm{S} 2030 \mathrm{~B}(Y=28.8, u$, $\left.=.181, v^{\prime}=.451\right) ; \mathrm{S} 3030 \mathrm{~B}\left(Y=20.5, u^{\prime}=.178, v^{\prime}=.447\right)$; S4030 B $\left(Y=14.5, u^{\prime}=.174, v^{\prime}=.441\right)$. The stimuli used provided a luminance variation from 34.6 to 18.4 for Staircase Y $(34.6 / 18.4=1.88)$ and from 28.8 to 14.5 for Staircase B $(28.8 / 14.5=1.97)$.

The reference sets were presented as in Experiment 1 (illuminated by $4000 \mathrm{~lx}, 5500 \mathrm{~K}$ ). There were three plates of the NCS atlas. One was the plate containing the color surface stimuli corresponding to the staircase. The other two were the plates with the nearest NCS-hue. For Staircase Y, the NCS plate identifications were G90Y, Y, and Y10R, and for Staircase B, R90B, B, and B10B.

\section{Design and Procedure}

An intragroup $3 \times 3$ (Number of Staircase Squares $\times$ Number of Backgrounds) design was used. The number of squares in the staircase changed between trials from 1 (only the lowest luminance stimulus) to 3 (the full staircase). For partial staircases (less than 3 stimuli), only the lowest luminances were used. The staircases (full or partial) were presented on 3 of the 4 backgrounds reproduced in Figure 1 (Gelb, Mondrian, and white insulation).

Twenty random orders (two for every participant) were created. Each sequence included the 9 experimental conditions resulting from combining the 3 possible staircases ( 1 to 3 squares) with the 3 backgrounds. Half of the sequences were used in the asymmetric lightness matching task, and the other half in the naming task.

Half of the participants performed the matching task before the naming task. As in Experiment 1, the matching task required the participant to indicate, from the stimuli contained in the accurate reference set, the stimulus that was the most similar to each staircase square. Half of the observers performed the naming task before the matching task. It required them to name every staircase stimulus using one (i.e., yellow) or two (i.e., green-yellow) color categories. Before beginning the naming task, every participant was informed that only some categories were allowed (their English equivalents in parenthesis): Rojo (red), Verde (green), 
Azul (blue), Amarillo (Yellow), Blanco (White), Negro (Black), Gris (Grey), Marrón (Brown), Rosa (Pink), Morado (Purple), and Naranja (Orange). We selected these terms because they correspond to the Spanish Basic Color Categories (Lillo, Moreira \& Vitini, in press) with direct correspondence to their English equivalents (Boynton \& Olson, 1987, 1990; Sturges \& Whitfield, 1997).

Participants were informed that they had three response possibilities: (a) using only one category (i.e., "yellow"), (b) using two categories without indicating predominance (i.e., "yellow and green"), and (c) using two categories but indicating some predominance (i.e., "more yellow than green").

\section{Results}

\section{Matched Reflectances}

Figures 5 and 6 display the most important results provided by the asymmetric matching task. Figure 5 corresponds to the trials were the full staircase was presented.

The information provided by Figures 3 (Experiment 1) and 5 (Experiment 2) are similar, except that Figure 5 concerns staircases with reduced relative luminance (Y/Yn) ranges. More specifically, in Figure 5.A (Staircase Y), the range goes from 18.4 to 34.6 (ratio 1.88) and in Figure 5.B (Staircase B), from 28.8 to 14.5 (ratio 1.97). In both cases, the Mondrian background produced a higher slope than the Gelb one, with the white insulation in an intermediate level. More specifically, the slopes for Staircase Y were 1.182 for the Mondrian $\left(r^{2}=.728\right), 0.906$ for the white insulation $\left(r^{2}\right.$ $=.558)$, and $0.779\left(r^{2}=.623\right)$ for the Gelb. In the case of Staircase B, the slopes were 1.170 for the Mondrian $\left(r^{2}=\right.$ $.679), 0.906$ for the white insulation $\left(r^{2}=.547\right)$, and 0.793 $\left(r^{2}=.698\right)$ for the Gelb. Consequently, the Gelb background produced a lightness compression effect (the reflectances of the matched stimuli produced a smaller "grey" scale).

Two repeated measures ANOVAs were performed to compare the selections obtained in the three backgrounds in response to the lowest luminance stimulus of the full staircase presented. Both of them indicated that background type produced significant differences, $F(2)=28.62, p<$ .05 , for Staircase Y; and $F(1,24)=23.10, p<.05$, for Staircase B . All the possible comparisons between pairs were significant $(p<.05)$ for Staircases Y and B, except for the comparison of the white insulation and Mondrian background for Staircase B.

Figure 6 shows the changes in the appearance of the lowest luminance stimulus as the number of the stimuli in the staircase increased. The slopes for Staircase Y were -0.302 for the Mondrian condition $\left(r^{2}=.140\right),-.188$ for the white insulation $\left(r^{2}=.038\right)$, and $-0.526\left(r^{2}=.259\right)$ for the Gelb condition. The slopes for Staircase B were -0.312 for the Mondrian $\left(r^{2}=.088\right),-0.159$ for the white insulation $\left(r^{2}=.019\right)$, and $-0.393\left(r^{2}=.226\right)$ for the Gelb condition.

A repeated measures parametric ANOVA was performed for every combination of background and staircase type. They indicated that the reflectances selected in response to the lowest luminance stimulus did not change significantly $(p>.05)$ as the staircase grew larger on the B-Mondrian, $F(2)=2.25$; the B-white insulation, $F(2)=1.31$; and the
A

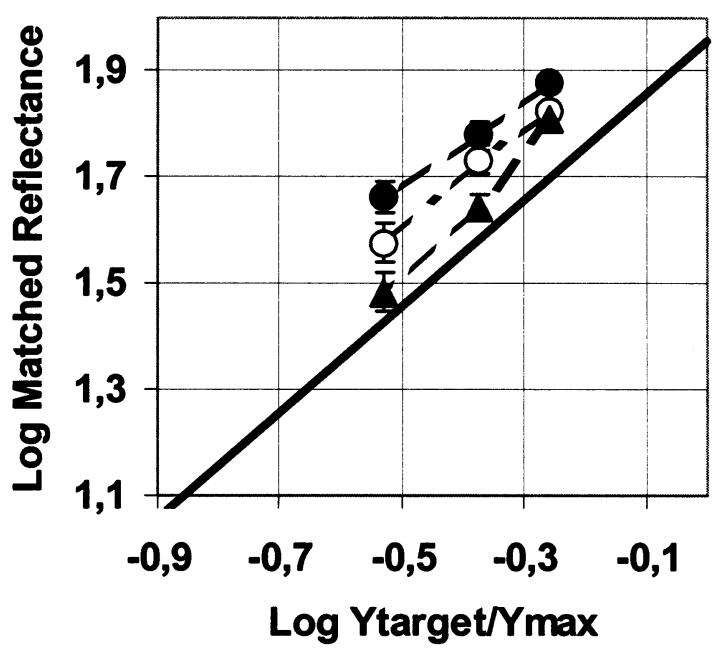

B

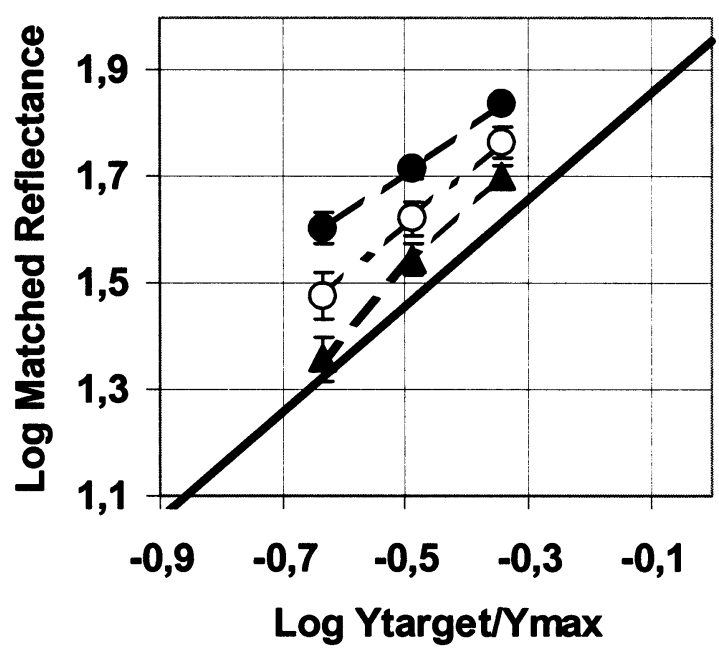

Figure 5. Asymmetric lightness matching for the full staircase presentation in Experiment 2 for Staircases Y (Figure 6.A) and B (Figure 6.B). The abscissa corresponds to the logarithm of the ratio between the square luminance (Ytarget) and the staircase maximum luminance (Ymax). The ordinate indicates matched luminances. Continuous lines correspond to a perfect correspondence between presented luminances and matched reflectances. Gelb = black circles, Mondrian = black triangles, and White insulation = white circles. 
6.A



6.B

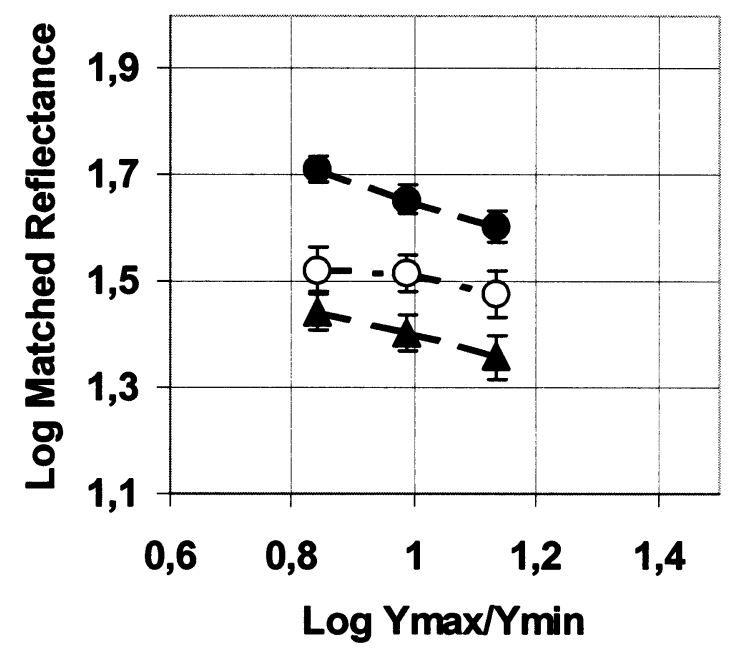

Figure 6. Changes in the appearance of the lower luminance stimulus in Experiment 2 for Staircases Y (Figure 6.A) and B (Figure 6.B). The abscissa indicates the logarithm of the ratio between the staircase maximum luminance (Ymax) and the target luminance (Ymin). The ordinate indicates matched reflectances. For every line, the most leftward point corresponds to the sole presentation of the lowest luminance stimulus. The most rightward point corresponds to its presentation in the full staircase.

Y-white insulation, $F(2)=1.61$. In contrast, they changed significantly $(p<.05)$ on the B-Gelb, $F(2)=7.92$; the YMondrian, $F(2)=3.73$; and the Y-Gelb, $F(2)=9.52$. For the last three conditions a multiple comparison analysis was performed. The only significant differences $(p<.05)$ were between the 1- and 3-step staircases for the B-Gelb and the Y-Gelb conditions.

\section{Matched Chromatic Angles}

Repeated measures ANOVAs were performed to compare, in each full staircase, the chromatic angles $\left(\mathrm{H}^{*}\right)$ of the selections corresponding to the three backgrounds in response to lowest luminance stimulus. Both of them indicated that background type produced no significant differences, $F(2)=1.61, p>.05$, for Staircase Y, and $F(2)$ $=0.51, p>.05$, for Staircase B.

Repeated measures parametric ANOVAs were performed for every combination of background and staircase type. For all the cases, no significant differences were observed.

\section{Naming Task}

As indicated previously, in the naming task, the participants used one or two chromatic categories to name the target stimuli. A 5-point rating scale was used to perform the statistical analysis. It was conceptually similar to the one used by Boynton and Gordon (1965). Its maximum score (4) corresponded to responding exclusively with the category that was the most closely related to the staircase NCS-hue denomination (yellow for $\mathrm{Y}$, blue for $\mathrm{B}$, hereafter
Category X). Its minimum score (0) corresponded to responding exclusively with any other category (hereafter Category Z). The other three scores corresponded to various $X-Z$ combinations $(3=$ more $X$ than $Z, 2=X$ equal to $Z ; 1$ $=$ more $Z$ than $X$ ). Given that in Staircase $B$, the exclusive use of blue was the predominant response for the six experimental conditions (the median was always 4 and no significant differences were detected), our commentaries will focus on the results corresponding to Staircase Y.

As when commenting other results, our initial intention was to include two figures in relation with the terms used in the naming task. The first one (Figure 7) corresponds to the naming of the full staircase. However, we decided to eliminate Figure 8 (related to the changes in the naming of the lowest luminance stimulus) because, for the Mondrian and white insulation backgrounds, the median value was 0 (the yellow category was used very infrequently). Consequently, for the Gelb background, the medians were 2, 0, and 1 for the 1-, 2-, and 3-step staircases, respectively.

A nonparametric Friedman analysis was performed for every background. Only for the Gelb were significant differences detected, $\chi^{2}(2)=12.33, p<.05$. The corresponding Wilcoxon analysis indicated that yellow was more frequently used in the Gelb background for the 1-step condition than in the 2-step, $Z=-2.41, p<.05$, or the 3 step conditions, $Z=-2.41, p<.05$.

Figure 7 provides information about naming the full $\mathrm{Y}$ Staircase. Its abscissa is the same as that in Figure 5.A and displays the staircase luminance (Log Ytarget/Ymax). As can be observed, the predominance of the use of yellow was highly influenced by the background. For the Mondrian, 
this category only was consistently used for the lightest staircase stimuli (the median for the other two stimuli was 0 ). For the Gelb, yellow was used more frequently (the median for the other two stimuli was 1 and 2). As can also be observed, the white insulation background produced intermediate results.

A nonparametric Friedman analysis indicated that the use of the yellow category when naming the lowest luminance stimulus depended of the background, $\chi^{2}(2)=$ $10, p<.05$. The corresponding Wilcoxon analysis indicated that yellow was more frequently used in the Gelb background than in any of the other two (for both comparisons, $Z=-2.12, p<.05)$.

A chromatic compression effect was observed for the Gelb background because: (a) When the full staircase was present, there were fewer hue-naming changes between the darker and the lighter stimulus in Gelb background than in the other two backgrounds $(p<.05)$; (b) only for the Gelb background, the naming of the darkest stimulus changed significantly ( $p$ $<.01)$ with the addition of more staircase stimuli.

\section{General Discussion}

In these two experiments, the lightness compression effect described by Gilchrist and Catalioti (1994) and Cataliotti and Gilchrist (1995) was replicated. In Experiment

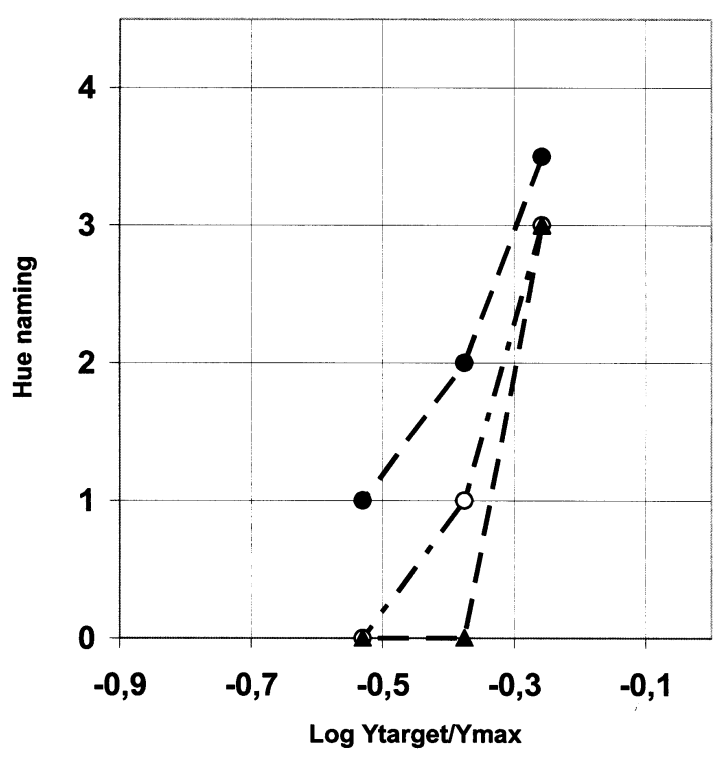

Figure 7. Naming task results for Staircase Y in Experiment 2. The abscissa corresponds to the logarithm of the ratio between the square luminance (Ytarget) and the maximum staircase luminance (Ymax). The ordinate informs about naming responses on a 5-point rating scale (ranging from 0 to 4). Four indicates naming only with yellow. Zero indicates naming only using an alternative category. Gelb = black circles, Mondrian = black triangles, White insulation $=$ white circles.
1, a truncated grey scale (from white to medium grey) was perceived when the staircase was the only stimulation presented in the near background (Gelb condition), but not when presented on a Mondrian background. Similarly, in Experiment 2, the Gelb condition produced less lightness variation for the full staircase than when presented on the other two backgrounds. In contrast, given that in Experiment 1, the nonadjacent Mondrian pattern produced a partial compression effect, our results are not fully concordant with the predictions of the anchoring theory (Gilchrist et al., 1999), and the relevance of local factors cannot be discarded as an explanation for the lightness compression effect.

Experiment 2 showed a clear relation between the magnitude of the lightness compression effect and hue perception changes for the susceptible chromatic angle. More specifically, for the full staircase presentations, the Gelb background produced maximum lightness compression (more similarity in the lightness of the staircase stimuli) and minimum B-B effect (fewer differences in hue). Second, and also concordant with the predictions derived from the anchoring theory, only for the Gelb condition, there were changes in the hue of the lowest luminance staircase stimuli associated with the increase in the staircase extension.

In a paper on the historical evolution of the concept of the articulation in relation with the understanding of lightness perception, Gilchrist and Annan (2002, p. 149) concluded that "articulation is a major factor in lightness perception, one that can produce effects on lightness just as strong as those produced by changing neighbouring luminance values." We believe that our results are a step towards concluding, in the near future, that articulation is a major factor in hue perception just as strong as chromatic angle (or dominant wavelength) and lightness. Let us we explain why.

The B-B effect was discovered in the $19^{\text {th }}$ century and studied during the entire $20^{\text {th }}$ century (for example, Haupt, 1922; Nagy, 1980; Pridmore, 1999a, 1999b; Takahaski \& Ejima, 1983; Walraven, 1961) and it is probably going to be an active research subject in the current century (Paramei, Bimler, \& Izmailov, 2005). Anyhow, it has commonly been considered "a second-order phenomenon" (Boynton \& Gordon, 1965, p. 78). That is, it has been habitual in the scientific-technological community to consider hue perception as strongly determined by dominant wavelength (or chromatic angle. See, for example, Sanders \& McCormick, 1993, p. 513). Because of this, the B-B effect is considered only "an effect," that is, something added on to the main relation (the relation between hue and chromatic angle). In our opinion, it is more correct to assume that, in surface colors, the more qualitative dimension of color perception-hue-is mainly determined by two psychophysical variables: one of a quantitative nature (relative luminance) and the other of a qualitative nature (dominant wavelength or chromatic angle).

In a previous paper (Lillo et al., 2004), we indicated that the systematic infravaloration of the importance of the 
B-B effect may be due to the frequent use of aperture colors when studying this effect. In the same paper, we showed (Table 2) that when using surface colors with the same chromatic angle, basic color category use changed depending on lightness variations for nearly half of the NCS color circle. In this context, it is very interesting to note what this table reveals about brown. As expected, this category was predominantly used for naming dark stimuli in the range of NCS-hues between G70Y $\left(\lambda_{D}=570\right.$, $\left.\mathrm{H}^{*} u^{\prime} v^{\prime}=84.85\right)$ and $\mathrm{R} 30 \mathrm{~B}\left(\lambda_{D}=-502.5, \mathrm{H}^{*} u^{\prime} v^{\prime}=\right.$ $343.33)$, but in the same range, brown was substituted by other categories when lighter stimuli were used. More specifically, by yellow from G70Y to Y30R, by orange from Y20R to Y60R, and by pink from Y40R to R30B. Taking this into account, experiments could be designed where the same group of stimuli (in terms of luminance and chromatic coordinates) could be named the same (brown) when perceived as dark, but differently (yellow, orange, or pink) when perceived as light. This prediction is only an extension of what was observed for Staircase Y Experiment 2 of this paper.

In addition to its utility for the experiment proposed above, Table 2 of Lillo et al. (2004) could be used for comparing the relative efficacy of lightness illusions such as the ones described by White (1981) and Adelson (1993). In accordance with the observations from our Experiment 2, the rule for the predictions can be stated as follows: The higher the efficacy for changing lightness perception, the greater the expected change in hue perception (for the susceptible chromatic angles indicated in Figure 2).

Going back to Experiment 2 of this paper, it is important to remember that we used achromatic backgrounds and two staircases with a reduced luminance variation. These factors probably contributed to making the results easily explainable from the current version of the anchoring theory (Gilchrist et al., 1999). In contrast, the very existence of what have traditionally been called "color contrast" and "color assimilation" (DeValois \& DeValois, 1988) leads us to consider likely a reformulation of the anchoring theory in order to provide a complete explanation of color perception. More specifically, although the reference white must determine lightness perception anchoring, hue perception must somehow depend on the chromatic variation provided by each spatial framework. The feasibility of this extension and modification of the anchoring theory will depend on the results provided by future experiments.

\section{References}

Adelson, E.H. (1993). Perceptual organization and the judgement of brightness. Science, 262, 2042-2044.

Boynton, R.M., \& Gordon, J. (1965). Bezold-Brücke shift measured by color-naming technique. Journal of the Optical Society of America, 55, 78-86.
Boynton, R.M., \& Olson, C.R. (1987). Locating basic colors in the OSA space. Colour Research and Application, 12, 94-105.

Boynton, R.M., \& Olson, C.X. (1990). Salience of chromatic basic color terms confirmed by three measures. Vision Research, 30, 1311-1317.

Cataliotti, J., \& Gilchrist, A.L. (1995). Local and global processes in surface lightness perception. Perception \& Psychophysics, 57, 125-135.

De Valois, R.L., \& De Valois, K.K. (1988). Spatial vision. Oxford: Oxford University Press.

Fletcher, R.J. (1980). The City University Color Vision Test $\left(2^{\text {nd }}\right.$ ed.). London: Keeler.

Gelb, A. (1929/1938). Die "Farbenkonstanz" der Sehdinge. In W.A. von Bethe, G. von Bergmann, G. Embden, \& A, Ellinger (Eds.), Handbuch der normalen und pathologischen Physiologie (pp. 594-678). Band 12, 1. Hälfte Receptionsorgane II. Berlin: Springer. [Selection translated in W.D. Ellis (Ed.), A source book of Gestalt psychology (pp. 196-209). New York: Harcourt Brace; London: Paul, Trench, Trubner].

Gilchrist, A.L., \& Annan, V., JR. (2002). Articulation effects in lightness: Historical backgrounds and theoretical implications. Perception, 4, 141-150.

Gilchrist, A.L., \& Cataliotti, J. (1994). Anchoring of surface lightness values with multiple illumination levels. Investigative Opthalmology and Visual Science, 35, S2165.

Gilchrist, A., Kossyfidis, C., Bonato, F., Agostini, T., Cataliotti, J., Li, X., Spehar, B., Annan, V., \& Economou, E. (1999). An anchoring theory of lightness perception. Psychological Review, 106, 795-834. Haupt, I.A. (1922). The selectiveness of the eye's response to wavelength and its change with change of intensity. Journal of Experimental Psychology, 5, 347-379.

Hunt, R.W.G. (1991). Measuring Colour (2 ${ }^{\text {nd }}$ Ed.). New York: Wiley. Kayser, P.K., \& Boynton, R.M. (1996). Human Color Vision (2 ${ }^{\text {nd }}$ ed.). Washington: Optical Society of America.

Lillo, J., Aguado, L., Moreira, H., \& Davies, I.R.L. (2004). Lightness and hue perception: The Bezold-Brücke effect and colour basic categories. Psicológica, 25, 23-44.

Lillo, J., Moreira, H., \& Gómez, N. (2002). Reflectance and energetic imbalance: Colourimetric evaluation of the NCS Colour Atlas. Psicológica, 23, 209-231.

Lillo, J., Moreira, H., \&Vitini, I. (in press). Locating Spanish basic colors in CIE L* $\mathrm{U}^{*} \mathrm{~V}^{*}$ space: Identification, lightness segregation and correspondence with English equivalents. Psicológica.

Nagy, A.L. (1980). Short-flash Bezold-Brücke hue shifts. Vision Research, 20, 361-368.

Paramei, G.V., Bimler, D.L., \& Izmailov, C.A. (2005). "Paint it black": Hue and saturation shifts from spatially induced blackness. Perception, 34. 157.

Pridmore, R.W. (1999a). Bezold-Brücke hue-shift as functions of luminance level, luminance ratio, interstimulus interval and adapting white for aperture and object colors. Vision Research, 39, 3873-3891.

Pridmore, R.W. (1999b). Unique and binary hues as functions of luminance and illuminant color temperature, and relations with invariant hues. Vision Research, 39, 3892-3908. 
Sanders, M.S., \& McCormick, E.J. (1993). Human factors in engineering and design ( $7^{\text {th }}$ ed.). New York: McGraw-Hill.

SCI. (1997). NCS Index Edition 2. Stockholm: Scandinavian Color Institute.

Sturges, J, \& Whitfield, A. (1997). Salient features of Munsell colour space as a function of monolexemic naming and response latencies. Vision Research, 37, 307-313.

Takahashi, S., \& Ejima, Y. (1983). Functional relationship between chromatic induction and luminance of inducing stimulus. Journal of the Optical Society of America, 73, 198202.

Uchikawa, U., Uchicawa, K., \& Boynton, R.M. (1989). Influence of achromatic surrounds on categorical perception of surface colors. Vision Research, 29, 881-890.Walraven, R.L. (1961). On the Bezold-Brücke phenomenon. Journal of the Optical Society of America, 51, 1113-1116.

White, M. (1981). The effect of the nature of the surround on the perceived lightness of grey bars within square-wave test gratings. Perception, 10, 215-230.

Wyszecki, G., \& Stiles, W.S. (1982). Color science: Concepts and methods. Quantitative data and formulae ( $2^{\text {nd }}$ ed.). New York: Wiley.

Received December 15, 2006 Review received July 7, 2006 Accepted July 21, 2006 